\title{
Sealing ability of amalgam, super EBA cement, and MTA when used as retrograde filling materials
}

\author{
J. Aqrabawi ${ }^{1}$
}

Objective To compare apical microleakage of MTA following reverse retrograde root filling with that following amalgam and EBA retrofilling.

Design Prospective random control trial.

Setting It was conducted at the University of Jordan in 1998. Materials and methods The root canals of 79 extracted teeth were instrumented and obturated with vertically condensed gutta-percha. Each tooth was apically resected and the apex was prepared ultrasonically to $3 \mathrm{~mm}$ depth and the root surface isolated with nail varnish. Teeth were divided randomly into three groups of 25 teeth each. First group was retrofilled with amalgam, second group with EBA and the third group with MTA. Following immersion in $1 \%$ methylene blue dye for 72 hours, the roots were sectioned and the depth of dye penetration was evaluated by a stereomicroscope at $\mathrm{x} 10$ magnification.

Interventions Super EBA is a reinforced zinc oxide cement based on a mixture of $32 \%$ eugenol and $68 \%$ ethoxy benzoic acid (EBA). MTA is a mineral trioxide aggregate cement (MTA) based on a mixture of sterile water.

Main outcome measures The sealing effectiveness of the retrograde filling materials used in this study was determined by their ability to inhibit dye penetration.

Results $56 \%$ of the group filled with amalgam and $20 \%$ of the group filled with EBA showed dye leakage beyond the retrofilling material whereas the MTA group showed none, two samples from MTA group were eliminated because of their fractured roots. The chi-squared test revealed a statistically significant difference among all three groups $(P<0.05)$.

Conclusion MTA cement provides a better seal than amalgam and EBA cement when used as retrograde filling, but the extrapolation of this result into a clinical practice may be questionable.

A picoectomy followed by retrograde filling is a well-established A procedure to treat teeth with persistent periapical infections and teeth in which conventional root canal therapy has failed.

The ideal root-end filling material should be easy to manipulate, radiopaque, dimensionally stable, nonabsorbable, and not affected by the presence of moisture. It should also adhere to the preparation walls and seal the root canal system, be non-toxic, well-tolerated by periapical tissues and promote healing. ${ }^{1}$ There is plethora

\footnotetext{
${ }^{1}$ Assistant Professor, Endodontics, Faculty of Dental Medicine, University of Jordan, Amman, Jordan

REFEREED PAPER

Received 25.03.99; accepted 16.09.99

(C) British Dental Journal 2000; 188: 266-268
}

of studies published concerning the sealing ability and biocompatability of retrograde filling materials. ${ }^{2-5}$

Many materials have been suggested as root-end filling materials, including reinforced zinc oxide-eugenol (Cavit), gutta percha, zinc oxide-eugenol, composite resin and gold foil. ${ }^{6}$ Amalgam has proved to be a successful material for retrograde filling, despite or perhaps because of its microleakage and expansion on setting. ${ }^{7}$ Super EBA is a reinforced zinc oxide cement; its liquid contains $32 \%$ eugenol and $68 \%$ ethoxy benzoic acid (EBA). Early attempts at using zinc oxide-eugenol as a retrograde filling materials failed, but reinforced cement based on a mixture of eugenol and EBA make it a contender. ${ }^{8}$ However, the literature contains conflicting results regarding its suitability for such an application. ${ }^{2,3,9}$

An experimental material, mineral trioxide aggregate (MTA), was recently reported to seal off all the pathways of communication between the root canal system and the external surface of the tooth. The principal compounds present in the mineral trioxide material are tricalcium silicate, tricalcium aluminate, tricalcium oxide, and silicate oxide. In addition, there are a few other mineral oxides which are responsible for the chemical and physical properties of the aggregate. On mixing the aggregate with water, hydration of the powder results in a colloidal gel which solidifies to a hard structure in less than 4 hours. ${ }^{9}$

The purpose of this investigation was to assess the effectiveness of MTA in providing an apical seal in comparison with amalgam, and Super EBA cement by using a dye penetration method.

\section{Materials and methods}

Seventy-nine freshly extracted, human, single-rooted upper central, lateral and canine teeth were collected and stored in saline. The clinical crowns were removed with a \# 557 Carbide bur in a highspeed handpiece. The working length was determined by subtracting $0.5 \mathrm{~mm}$ from the length at which \# $15 \mathrm{~K}$ file appeared at the apical foramen. The apical portion of the root canal was prepared to a \# $40 \mathrm{~K}$ file and the rest of the canal was flared using a conventional step-back technique. $\mathrm{NaOCl} 5.25 \%$ was used as the irrigant.

The cleaned and shaped canals were dried with paper points and obturated with vertically condensed gutta-percha and Kerr's pulp canal sealer. The access opening was sealed with IRM (ID Caulk, Milford, DE). IRM is an intermediate restorative material which is a reinforced zinc oxide-eugenol.

The roots were then stored at room temperature and 100\% humidity for 1 week. Apical root resections were performed on all roots by removing $3 \mathrm{~mm}$ of each apex at 90 degrees to the long axis of the tooth with a \# 701 fissure bur in a high-speed handpiece with water coolant.

A $3 \mathrm{~mm}$ deep root-end cavity was prepared with an ultrasonic tip, powered by an ultrasonic unit (Excellence in Endodontics/ Analytic Technology, Orange, CA). Two coats of nail polish were 
then applied to the whole surface of the total length of each root except the tip of the root where the retrograde filling was to be applied. The teeth were assigned randomly into three groups of 25 roots each. Group 1 was retrofilled with high copper amalgam (Dispersalloy; Johnson \& Johnson, East Windsor, NY), Group 2 with Super EBA (Harry J Bosworth Co, Skokie, IL), and Group 3 with MTA (Loma Linda University, Loma Linda, CA). This was mixed with water to a putty consistency using a powder to water ratio of 3:1. Each of the materials was condensed into the preparation using small pluggers.

Two instrumented roots with retro-preparations received no retrograde filling, and these were used as positive controls. Another two roots were instrumented and obturated with guttapercha and sealer; their entire root surfaces were covered with two coats of nail polish and were used as negative controls. All roots were stored in $1 \%$ solution of methylene blue for 72 hours, after which the roots were rinsed under tap water, and the nail polish was removed. The teeth were then sectioned buccolingually using a tapered fissure bur in a high-speed handpiece to nearly the depth of the canal. They were then fractured with the end of a large spoon excavator. The depth of dye penetration was evaluated by a stereomicroscope at a magnification of x10 (Zeiss SV; Oberkochem, Germany). The roots were evaluated and scored as either acceptable or unacceptable. An acceptable score was defined as either no leakage or leakage that did not extend beyond the retrofilling material into the root canal space. An unacceptable score was defined as any leakage that extended beyond the retrofilling material into the root canal space. Statistical analysis of the results was performed using the chi-squared test.

\section{Results}

The positive control samples showed dye leakage throughout the length of the canals, while the negative control samples had no dye penetration.

Two roots from Group 3 were eliminated from the study because they exhibited a vertical fracture that allowed dye penetration into the root canal system.

The results (Table 1) from Group 1 (amalgam) showed that 14 (56\%) of 25 samples were scored as unacceptable (Fig. 1) because dye leakage was found in the root canal space beyond the retrofilling material. From Group 2 (EBA) 5 (20\%) of 25 specimens were scored unacceptable (Fig.2). All 23 specimens in Group 3 (MTA) were scored as acceptable (Fig. 3 ) because no leakage was shown.

The data from all three groups were submitted for statistical analysis. The chi-squared tests revealed a statistically significant difference between Groups 1 and $2(P<0.01)$ and between Groups 1 and $3(P<0.009)$. The difference between Groups 2 and 3 (EBA and MTA) was also significant $(P<0.05)$.

Table 1 Results of leakage for the retrofilling materials

\begin{tabular}{lccc}
\hline Material & No. of samples & Acceptable & Unacceptable \\
\hline \multirow{3}{*}{ Amalgam } & 25 & 11 & 14 \\
EBA & 25 & 20 & 5 \\
MTA & 23 & 23 & 0 \\
\hline
\end{tabular}

\section{Discussion}

The purpose of placing a root end filling material is to provide an apical seal which inhibits the leakage of irritants from the root canal system into the periradicular tissues. Dye leakage to the full extent of the retrofilling material or beyond was considered as total leakage within the parameters of this study. When dye was prevented from penetrating the full extent of the retrofilling material it was considered that an adequate seal has been provided. With these criteria, it was not deemed necessary to measure linear leakage of the dye along the retrofilling materials.

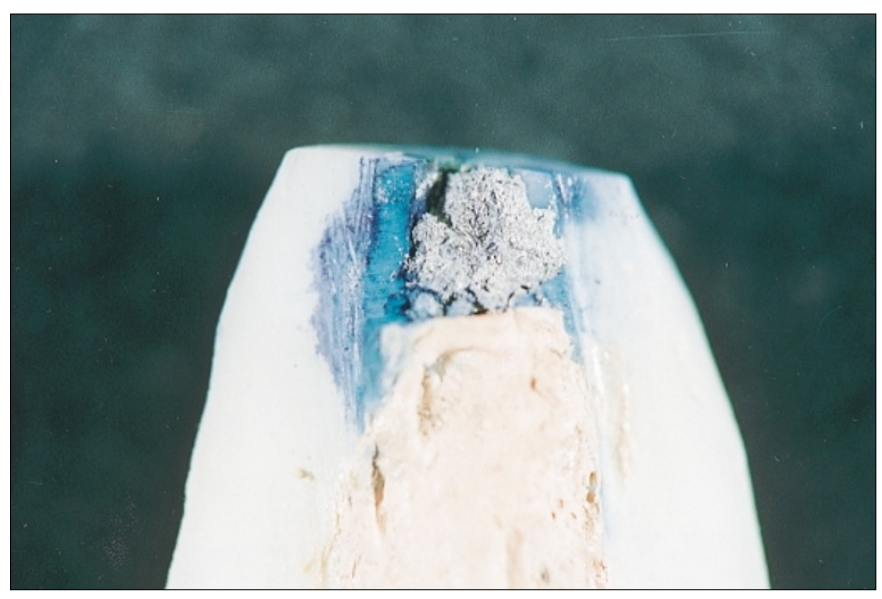

Fig. 1 Methylene blue dye penetration beyond the amalgam retrograde filling material

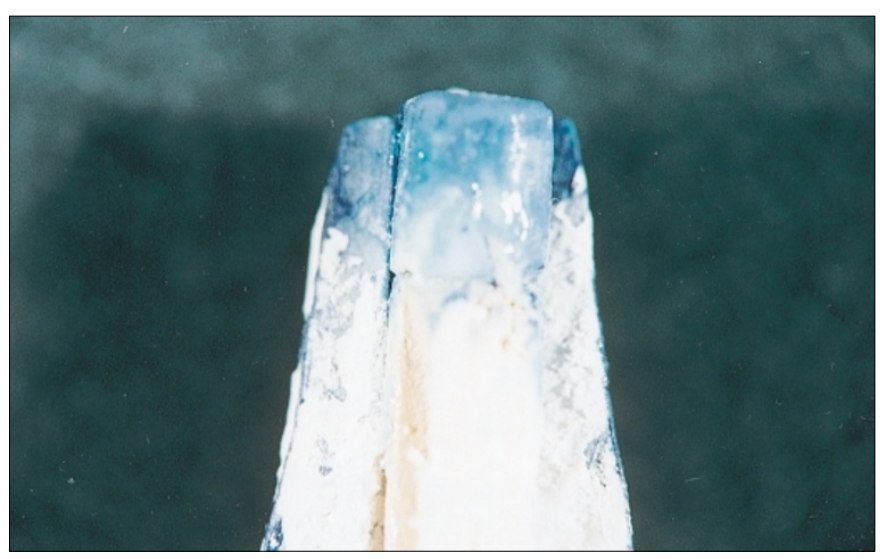

Fig. 2 Methylene blue dye penetration beyond the super EBA retrograde filling material

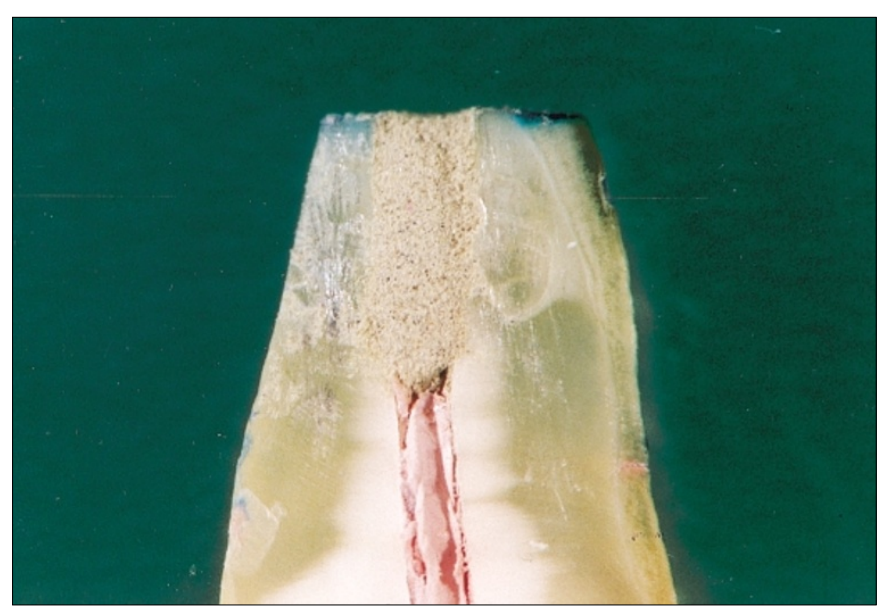

Fig 3. No methylene blue dye penetration was shown with MT aggregate when used as a retrograde filling material

Although amalgam generally has been the most commonly used root end filling material, it has a number of disadvantages such as scattering of amalgam particles into the surrounding tissues, corrosion, and setting properties which allow dimensional changes and fluid leakage. The leakage data obtained in this study agreed with the findings of Gerhard and Wagner ${ }^{10}$ and Chong et al.,11 and showed that all of the amalgam root end fillings leaked with the maximum dye leakage scores. The findings of our study confirmed the findings of other in vitro studies which showed that 
amalgam without the application of cavity varnish provides an inadequate seal. ${ }^{12-14}$

Because of the disadvantages with the use of amalgam as a root end filling material, zinc oxide-eugenol compounds such as EBA cement have been considered as alternative root end filling materials. ${ }^{15}$ However, leakage studies on the use of EBA cement as a retrograde filling material show conflicting results. Torabinejad et al., ${ }^{9}$ using rhodamine B fluorescent dye and a confocal microscope found that mineral trioxide aggregate (MTA) leaked significantly less than amalgam and Super EBA. During a 1-year period, using a fluid transport model, Wu et al., found glass ionomer cements and MTA leaked less than amalgam and EBA cement. ${ }^{16}$ A bacterial leakage study ${ }^{17}$ to determine the time needed for Serratia marcescens to penetrate a $3 \mathrm{~mm}$ thickness of amalgam, IRM, EBA cement, and MTA when these materials were used as root end filling materials, showed that mineral trioxide aggregate (MTA) was the most effective root end filling material against penetration of $S$. marcescens. The results of our study agrees with these studies. ${ }^{9,16,17}$ Our data indicated that MT aggregate showed less dye leakage compared with amalgam and EBA cement.

Although the results of this study showed that the MT aggregate has the potential of being used as a root end filling material because it provides an hermetic seal, direct extrapolation and relevance of dye leakage studies to clinical and practice application are questioned. Dye studies, however, are the easiest method to screen new restorative filling materials. When a filling material does not allow penetration of small molecules, it has the potential to prevent leakage of larger substances such as bacteria and their byproducts. Further studies are needed to determine the suitability of this material for in vivo use.
1 Gartner A H, Dorn S O. Advances in endodontic surgery. Dent Clin North Am 1992; 36: 357-379.

2 Beltes P, Zervas P, Lambrianidis T, Moylvdas I. In vitro study of the sealing ability of four retrograde filling materials. Endod Dent Traumatol 1988; 4: 82-84.

3 Bondra D L, Hartwell G R, MacPherson M G, Portell F R. Leakage in vitro with IRM, high copper amalgam and EBA cements as retrofilling materials. JEndodon 1989; 15: 157-160.

4 Barry G N, Selbst A G, Anton E W, Madden R M. Sealing ability of polycarboxylate cement when compared to amalgam as retrofilling material. Oral Surg 1976; 42: 109-116.

5 Kaplan S D, Tanzilli J P, Raphael D and Moodnik R M. A comparison of the marginal leakage of retrograde techniques. Oral Surg 1982; 54: 583-585.

6 Arens D E, Adams W R, D Castro R A (eds). Endodontic surgery. pp154157. Philadelphia: Harbor \& Row, 1981.

7 Zetterqvist L, Anneroth G, Danin J, Roding K. Microleakage of retrograde fillings. A comparative study between amalgam and glass ionomer cement in vitro. Int Endod J 1988; 21: 1-8.

8 Onynick J, Onynic T. A study of a new material for retrograde fillings. J Endodon 1978; 4: 203-206.

9 Torabinejad M, Watson T F, Pitt Ford T R. Sealing ability of Mineral Trioxide Aggregate when used as a root end filling material. J Endodon 1993; 19: 591-595.

10 Gerhard F, Wagner W. Sealing ability of five different retrograde filling materials. J Endodon 1996; 22: 463-466.

11 Chong B S, Pitt Ford T R, Watson T F. The adaptation and sealing ability of light-cured glass ionomer retrograde fillings. Int Endod J 1991; 24: 223-232.

12 Abdal A K, Retief D H, Jamison H C. The apical seal via the retrosurgical approach. 1. A preliminary study. Oral Surg 1982; 53: 614-621.

13 Barkhordar R A, Pelzner R B, Stark M M. Use of glass ionomer as a retrofilling materials. Oral Surg 1989; 67: 734-739.

14 Schwartz S A, Alexander J B. A comparison of leakage between silver glass ionomer cement and amalgam retrofillings. J Endodon 1988; 8: 385-391.

15 Szeremeta-Browar T L, VanCura J E, Zaki A E. A comparison of the sealing properties of different retrograde techniques : an autoradiographic study. Oral Surg Oral Med Oral Pathol 1985; 59: 82-87.

16 Wu M-K, Kontakiotis E G, Wesselink P R. Long-term seal provided by some root end filling materials. J Endodon 1998; 24: 557-560.

17 Fischer E J, Arens D E, Miller C H. Bacterial leakage of mineral trioxide aggregate as compared with zinc-free amalgam, intermediate restorative material, and super-EBA as a root-end filling material. J Endodon 1998; 24: 176-179. 